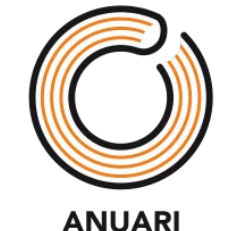

DE BIBLIOTEOUES,

LLIBRES I LECTURA

Antoni Daura i Jorba

adaura@parcir.com

Llibreria Parcir (Manresa)

President del Gremi de Llibreters de Catalunya (2010-2018)

\title{
LA PROMOCIÓ DE LA LECTURA \\ A LES LLIBRERIES DE CATALUNYA (2018-2019)
}

\author{
LA PROMOCIÓN DE LA LECTURA \\ EN LAS LIBRERÍAS DE CATALUÑA (2018-2019)
}

CATALAN BOOKSHOPS

AS PROMOTERS OF READING (2018-2019) 


\section{RESUM | RESUMEN | ABSTRACT}

La majoria de llibreries catalanes han estat tradicionalment un punt de trobada entre lectors i autors. De manera regular, les presentacions i signatures de llibres, com també les sessions de contacontes i, en menor grau, els clubs de lectura formen part del dia a dia de l'univers llibreter. Aquest paper es fa de manera natural, sense grans innovacions perquè es tracta d'un model plenament consolidat $i$ adient a les característiques, físiques i humanes, d'aquests establiments culturals de proximitat. En aquest informe repassarem la situació dels darrers dos anys.

La mayoría de librerías catalanas ha sido tradicionalmente un punto de encuentro entre lectores y autores. De manera regular las presentaciones y firmas de libros, así como las sesiones de cuentacuentos y, en menor grado, los clubes de lectura forman parte del día a día del universo librero. Este papel se juega de manera natural, sin grandes innovaciones porque se trata de un modelo plenamente consolidado y adecuado a las características, físicas y humanas, de estos establecimientos culturales de proximidad. En este informe repasaremos la situación de los últimos dos años.

Most Catalan bookshops have traditionally served as a meeting point between readers and authors. Regular book launches, signings, storytelling sessions and, to a lesser extent, reading clubs are part of daily life in the world of booksellers. They perform this role in a natural manner, without any great innovations, since the model is well established and perfectly suited to the physical and human characteristics of these local cultural facilities. This report will provide an overview of the situation over the last two years.

PARAULES CLAU:

Llibreries, Promoció de la lectura, Hàbits lectors, Estadístiques culturals,

Mercat del llibre

PALABRAS CLAVE:

06/04/2020

Librerías, Promoción de la lectura, Hábitos lectores, Estadísticas culturales,

Mercado del libro

KEYWORDS:

Bookshops, Reading promotion, Reading habits, Cultural statistics, Book trade 


\section{INTRODUCCIÓ}

L'activitat cultural de les llibreries a Catalunya s'ha mantingut, aquests darrers dos anys, força uniforme i invariable respecte d'exercicis anteriors. Segurament això és així, perquè es tracta d'un model de promoció molt efectiu i consolidat, ben adaptat al públic i a l'entorn on es troben ubicades les llibreries. Per aquesta raó, m'estalvio de fer determinades descripcions i reflexions i remeto el lector als informes precedents, on s'explica amb prou detall la idiosincràsia de les nostres llibreries i la manera que tenen d'organitzar i preparar aquests tipus d'esdeveniments. Val a dir que els analistes que darrerament estan estudiant i proposant un nou marc de promoció del comerç de proximitat insisteixen força en la necessitat de fer viure al client una experiència atractiva i singular. És el que s'anomena comerç experiencial, del qual ja hi ha força empreses que donen cursos $\mathrm{i}$ propostes concretes en àmbits diversos com ara les fires o el sector turístic. En el nostre cas, és la manera de competir davant dels nous models de comerç en línia que disposen d'uns grans catàlegs i serveixen a domicili. Doncs bé, les llibreries des de sempre han acostat els lectors als autors dels llibres que llegeixen d'una manera molt personalitzada i adaptada a les característiques de cada establiment.

\section{PROMOCIÓ GENERAL}

\subsection{Informació oficial}

Disposem realment de pocs indicadors, amb dades concretes i fiables, de l'activitat cultural de les llibreries en general. Si pouem als informes oficials veurem com es manté la tendència al fet que siguin les llibreries independents les que realment aposten més per promoure activitats de dinamització de la lectura. Al darrer Mapa de Llibreries de Catalunya, publicat el 2016 i presentat l'any 2017 pel Departament de Cultura de la Generalitat, això es reflectia clarament amb una diferència de 3,5 punts respecte a les cadenes. I, a més, s'ha de tenir en compte que els comerços multiproducte amb secció de llibres, com les grans superfícies, no fan cap tipus d'activitat. Restem a l'espera de poder tenir l'actualització del Mapa, si bé sospitem que la realitat no canviarà pas gaire globalment parlant.

Sí que tenim actualitzat l'informe Siegel, que forma part de l'Observatorio de la librería, publicat a finals de 2019 per la Confederación Española de Gremios y Asociaciones de Libreros i el Ministerio de Cultura y Deporte, amb dades d'àmbit estatal. S'apunta allí que el 75,8 \% de les llibreries duen
El comerç experiencial és la manera de competir de les Ilibreries davant dels nous models de comerç en línia

Es manté la tendència al fet que siguin les llibreries

independents les que realment aposten més per promoure activitats de dinamització de la lectura

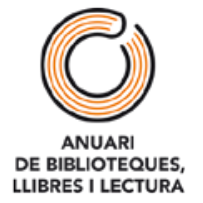


a terme les activitats clàssiques de signatures i presentacions, el 36,3\% programen contacontes infantils, el $29,3 \%$ disposen d'algun club de lectura propi i el 24,8 \% fan animació i activitats a escoles i biblioteques. Lamentablement, no sabem el perfil de les llibreries, si són grans, petites i/o independents.

Cal comentar també que al darrer informe fèiem referència al Pla de lectura 2020, presentat pel Departament de Cultura del govern de Catalunya. Allí hi havia una aposta seriosa, transversal, amb la voluntat d'enfortir el paper prescriptor de les llibreries i que aquestes poguessin ser més actives a l'hora de promocionar la lectura. Precisament el distintiu de qualitat, anomenat Llibreria de referència de Catalunya, empès pel mateix Departament, el Gremi de Llibreters de Catalunya i l'avaluació tècnica d'AENOR, té molt present l'activitat cultural de les llibreries. Avui hi ha setze llibreries reconegudes. Lamentablement aquest pla no s'ha pogut desenvolupar plenament per problemes pressupostaris, derivats de la situació política actual, amb la qual cosa no s'ha avançat gens.

Tanmateix, sí que s'ha mantingut la línia de subvencions a la modernització de llibreries. Per accedir-hi, un dels requisits principals és tenir una programació cultural estable al llarg de tot l'any. Així disposem de la informació següent, oferta per l'Institut Català de les Empreses Culturals on hi ha el llistat de les llibreries que fan activitat promocional a Catalunya:

\section{LLIBRERIES SUBVENCIONADES EL 2018}

Convocatòria: Modernització de Llibreries

- Alba Martí Busquets

- ALIBRI Librería, SL

- Andrea Giovannoli

- Anna Soler Esteller

- Atelier Libros, SA

- Bauça i Vila Electrónica, SL

- Buc de Llibres, SCCL

- Carles Ramon Mansa

- Casa Usher Llibreters, SL

- Cecilia Picún Fuentes

- Companyia Central Llibretera, SL

- Cultural Rocaguinarda, SCCL

- Desván del Lector Llibreters, SL

- Distribución y Edición de Librerías, SA

- Editorial Claret, SLU

- Editorial de Música Boileau, SL

- El Tramvia de Mataró, SL

- Els Nou Rals, SCCL

- Fe Fernández Villaret

- Fernando Velasco Chapinal
Hi ha setze llibreries reconegudes amb el distintiu de qualitat anomenat Llibreria de referència de Catalunya

\section{S'ha mantingut la}

línia de subvencions a la modernització de llibreries, un dels requisits principals és tenir una programació cultural estable al llarg de tot l'any 
- Flamma Tea, SL

- Galatea Llibres, SLU

- German Machado Lens

- Gorigiba, SL

- Grama-Llibres, SL

- Irene Bonet Martín

- Jaimes, SLU

- Josep Mitjans Benach

- Karim Kemmat

- La Caixa d'Eines, SL

- La Carbonera Llibreria, SCCL

- La Gralla, SCCL

- La Impossible, SCCL

- Laietana de Llibreteria, SL

- Llibreria A Peu de Pàgina, SLNE

- Llibreria Adserà, SL

- Llibreria Anglesa, SL

- Llibreria Antinous, SL

- Llibreria Aqualata, SL

- Llibreria Cinta, SL

- Llibreria L'Altell, SL

- Llibreria La Llopa, SL

- Llibreria Sendak, SCCL

- Llibreria Viladrich, SL

- Llibres Parcir, SL

- Mar Soledad Ferrer Arpa

- Marcombo, SA

- Maria Pagès Sáez

- Marina Meneses Amate

- Marta Farré Corbera

- Marta Gil Soler

- Muntanya de Llibres, SLU

- Nollegiu, SL

- Olivia Pascual Pastor

- Oriol Massó Barnadas

- Papereria llibreria Campus, SL

- Papereria llibreria Núria, SL

- Perutxo Llibres, SL

- Procultura, SL

- Racó del Llibre, SL

- Ramon Inglada Juncosa

- Saltamartí Llibres, SA

- Tapide, SA

- Wordsinprogress, SL 


\section{LLIBRERIES SUBVENCIONADES EL 2019}

Convocatòria: Modernització de Llibreries

- Abacus, SCCL

- Andrea Giovannoli

- Anna Soler Esteller

- Atelier Libros, SA

- Carles Ramon Mansa

- Carolina Maria Porta Pacín

- Casa Usher Llibreters, SL

- Cecilia Picún Fuentes

- Compañía Latinoamericana de Libros, SL

- Companya Central Llibretera, SL

- Cultural Rocaguinarda, SCCL

- Distribución y Edición de Librerías, SA

- Distribución y Edición de Librerías, SA

- Dòria Llibres, SL

- Editorial Claret, SLU

- El Tramvia de Mataró, SL

- Els Nou Rals, SCCL

- Fe Fernández Villaret

- Fernando Velasco Chapinal

- Flamma Tea, SL

- Galatea Llibres, SLU

- Germán Machado Lens

- Gorigiba, SL

- Grama-Llibres, SL

- Irene Bonet Martín

- Jaimes, SLU

- Josefina Sala Pujol

- La Caixa d'Eines, SL

- La Carbonera Llibreria, SCCL

- La Gralla, SCCL

- La Impossible, SCCL

- Laietana De Llibreteria, SL

- Llibreria Adserà, SL

- Llibreria Al·lots, SL

- Llibreria Altair, SL

- Llibreria Anglesa, SL

- Llibreria Antinous, SL

- Llibreria Aqualata, SL

- Llibreria Gallissà, SL

- Llibreria Gaudí, SCP

- Llibreria L'Altell, SL

- Llibreria Pebre Negre, SCCL

- Llibreria Sendak, SCCL

- Llibreria Viladrich, SL

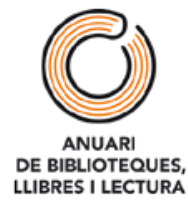


- Llibres Parcir, SL

- Marcombo, SA

- Maria Soledad Ferrer Arpa

- Marina Meneses Amate

- Marta Farré Corbera

- Marta Gil Soler

- Muntanya de Llibres, SLU

- Niudelletres, SL

- Nollegiu, SL

- Nuria Nájera Rosa

- Olivia Pascual Pastor

- Oriol Massó Barnadas

- Procultura, SL (Llibreria Documenta)

- Punt de Llibre, SL

- Racó del Llibre, SL

- Ramon Inglada Juncosa

- Saltamartí Llibres, SA

- Sergio Bassa Giralt

- Silvia Keryova

- Tapide, SA

- Wordsinprogress, SL

\subsection{Informació gremial}

Les dades recollides $\mathrm{i}$ aportades pel Gremi de Llibreters de Catalunya són molt parcials, perquè depenen sobretot de la informació que cada llibreria vulgui oferir $i$ que es publiquen regularment a la web $i$ al Twitter corporatius: www.gremidellibreters.cat i @Llibreterscat, respectivament. Un resum de les activitats de les quals el Gremi s'ha fet ressò dona el resultat següent pel que fa a l'any 2019. De l'anterior, no en tenim dades:

El premi Llibreter que el 2019 arribà a la vintena edició
- Presentacions de llibres:

- Activitats infantils:

- Clubs de lectura:

- Tallers:

- Llibres i música:

- Participació a fires i/o festes literàries:

\author{
1.600 actes \\ 700 propostes \\ 1.000 trobades \\ 400 sessions \\ 150 concerts \\ 80 (exclòs Sant Jordi)
}

Per altra banda, un repàs a les llibreries agremiades (284 l'any 2019) permet observar com el $93 \%$ disposen de pàgina web on reflecteixen les seves activitats. Això vol dir que, llevat de casos puntuals en què la venda de llibres no és l'activitat comercial principal, la majoria hi presenta un apartat específic, la qual cosa demostra que la importància que hom dona a aquest àmbit promocional és plenament compartida per tothom.

Convé recordar, al mateix temps, el paper promocional que fa el Gremi en conjunt amb el premi Llibreter que el 2019 arribà a la vintena edició, i durant el Dia del Llibre, el 23 d'abril, Sant Jordi.

De les Ilibreries

agremiades (284 l'any

2019), el $93 \%$

disposen de pàgina

web on reflecteixen

les seves activitats 


\subsection{Informació del portal Libelista}

Una altra font d'informació l'ofereix el portal Libelista. Va néixer l'any 2012, per iniciativa del Gremi de Llibreters de Catalunya, amb el nom de Liberdrac. Inicialment, només era una plataforma per donar servei a les llibreries en la venda de llibres electrònics. L'any 2015 l'empresa fa una ampliació de capital i hi entren nous socis i passa a oferir també venda de llibre convencional en paper. Alhora es canvia la denominació i es converteix al mateix temps en un portal que pretén oferir un servei comercial global, partint de la gestió dels estocs de les llibreries participants, que, al mateix temps, reben el suport logístic i promocional conjunt de Libelista. I té una agenda dels actes i l'activitat cultural de les llibreries de la xarxa, permanentment actualitzada i activa.

Seguidament, referenciem la informació facilitada per Gerard Almirall, responsable de continguts de la plataforma.

Libelista agrupa cent cinquanta-quatre Ilibreries de tot l'Estat espanyol. En la seva pàgina, les llibreries associades poden pujar i compartir totes les activitats i esdeveniments culturals que organitzin, per donar-los més difusió i arribar a un major nombre d'usuaris.

La plataforma permet inserir la imatge del cartell, tota la informació pràctica de l'esdeveniment (data, hora, localització, cost de l'activitat, etc.), un enllaç a la pàgina on es pot trobar tota la informació d'aquest esdeveniment i el formulari d'inscripció (en cas d'haver-n'hi) i un camp de text on afegir la descripció de l'activitat.

Aquestes activitats es divideixen en tres apartats:

- Activitats infantils: contacontes, tallers d'escriptura i lectura, presentacions de llibres infantils, etc.

- Presentacions i signatures de llibres en general.

- Activitats literàries (tallers d'escriptura, clubs de lectura, etc.).

Si bé inicialment s'oferia la possibilitat que cada llibreria apuntés les seves activitats, no ha estat fins als darrers temps, en què s'ha millorat i sistematitzat l'aplicació, que tenim dades fiables a exposar. A data d'avui i començant a comptar des del dia 28 de novembre de 2019 , que és quan es va desenvolupar la pàgina web actual, fins al 12 de març de 2020, disposem d'un històric a l'agenda de 245 esdeveniments, organitzats per trenta-una Ilibreries, el $20,12 \%$ de totes les llibreries de la plataforma.

Si es tenen en compte aquestes dades, podem dir que en cent sis dies cada llibreria va organitzar una mitjana de 7,9 activitats durant aquest període. També podem concloure que cada llibreria va oferir una mitjana d'una activitat cada 13,4 dies.
L'any 2015, Libelista fa una ampliació de capital i hi entren nous socis i passa a oferir també venda de llibre convencional en paper

Libelista té una agenda dels actes $i$ l'activitat cultural de les llibreries de la xarxa, permanentment actualitzada i activa

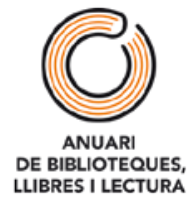


Tot i així, trobem una gran disparitat entre les llibreries més actives i les que ho són menys. La llibreria més activa ha organitzat trenta-dues activitats, mentre que trobem nou llibreries que només n'han ofert una.

També constatem que un mínim de cent cinc llibreries presents a la plataforma (el $68,18 \%$ del total) han organitzat com a mínim una activitat en aquest període, però només trenta-una han utilitzat la plataforma per fer-ne difusió, i s'han limitat a anunciar-les per les seves xarxes socials i/o publitramesa.

Aquests 245 esdeveniments, pujats i actualitzats per les mateixes llibreries, es divideixen en:

- Cent-una activitats infantils (el $41,22 \%$ ).

- Noranta-cinc presentacions i signatures de llibres (38,77\%).

- Quaranta-nou activitats literàries (20,01\%).

Quant al cobrament per part de les llibreries d'aquestes activitats, trobem les dades següents:

- Vuitanta-tres activitats infantils van ser de cobrament (el $82,17 \%$ de totes les activitats infantils), mentre que divuit activitats es van oferir de franc $(17,83 \%)$.

- Vuit presentacions i signatures de llibres van ser de cobrament (el 8,42 $\%$ del total de presentacions), mentre que vuitanta-set presentacions van ser de franc (91,57\%).

- Quaranta-sis activitats literàries van ser de cobrament $(93,87 \%$ del total), mentre que tres es van oferir de franc $(6,12 \%)$.

La nostra conclusió és que la majoria de llibreries pertanyents al grup encara no utilitzen totes les eines a la seva disposició per fer arribar les activitats dinamitzadores i promocionals culturals a un major nombre d'usuaris. Les poques que ho fan, en canvi, mostren un ús reiterat de la plataforma, i la utilitzen com una eina més, a la mateixa alçada que els seus perfils digitals a les xarxes socials.

A més, la majoria d'activitats ofertes per les llibreries de Libelista han estat relacionades amb el llibre infantil. Aquestes activitats, predominantment contacontes, són majoritàriament de pagament, i aporten així uns ingressos més o menys estables a les llibreries organitzadores.

Les presentacions de llibres, un format molt més tradicional i típic, segueixen sent freqüents, i en aquest cas se sol seguir el format d'oferir-se de franc als usuaris, tot i que normalment implica que el lector hagi d'adquirir el llibre, si el vol signat.
La majoria d'activitats

ofertes per les

llibreries han estat

relacionades amb el

llibre infantil.

Aquestes activitats,

predominantment

contacontes, són

majoritàriament de

pagament

Les presentacions de

Ilibres, un format molt

més tradicional i típic, segueixen sent

freqüents, i en aquest

cas se sol seguir el

format d'oferir-se de

franc als usuaris, 


\section{Plataforma Libelista}

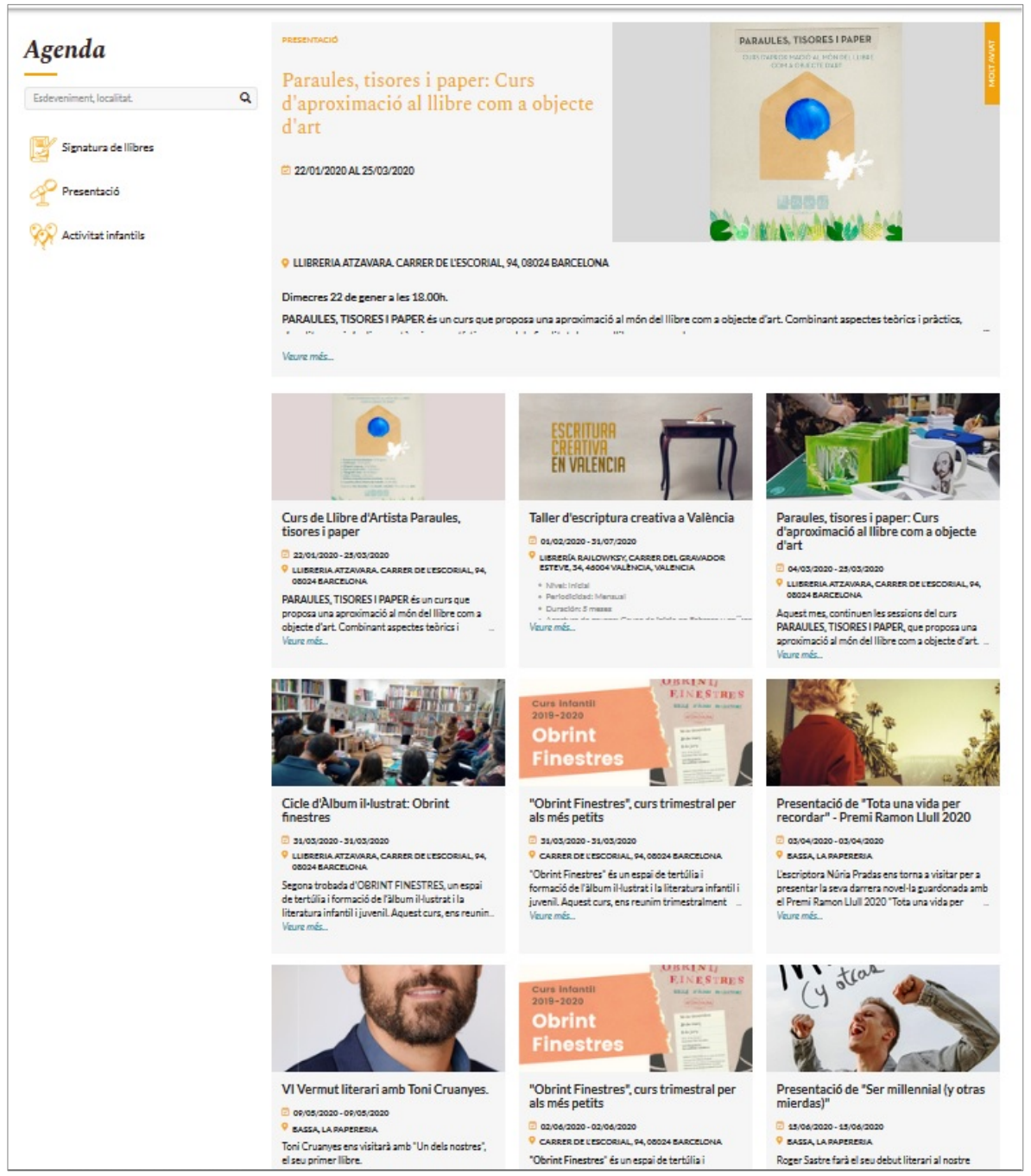

Activitat de les llibreries a la plataforma Libelista
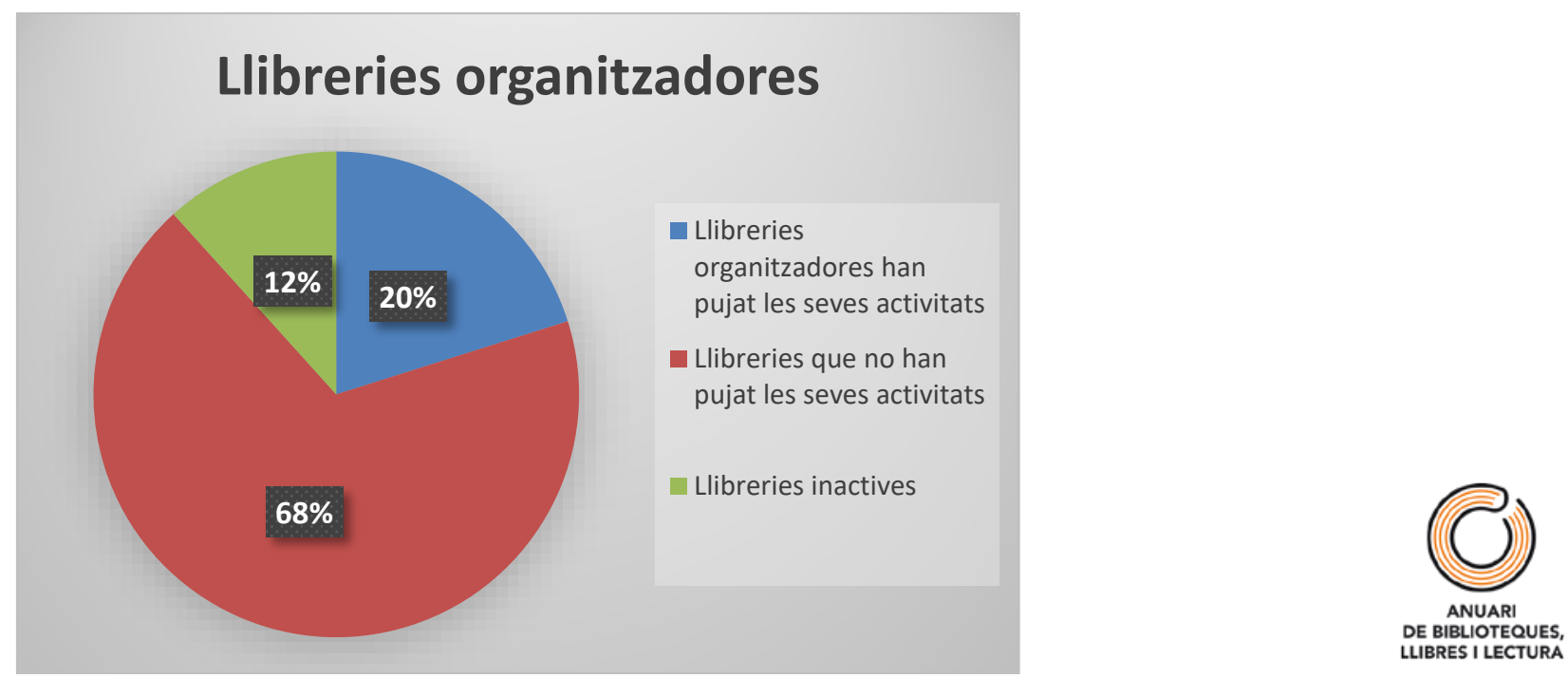


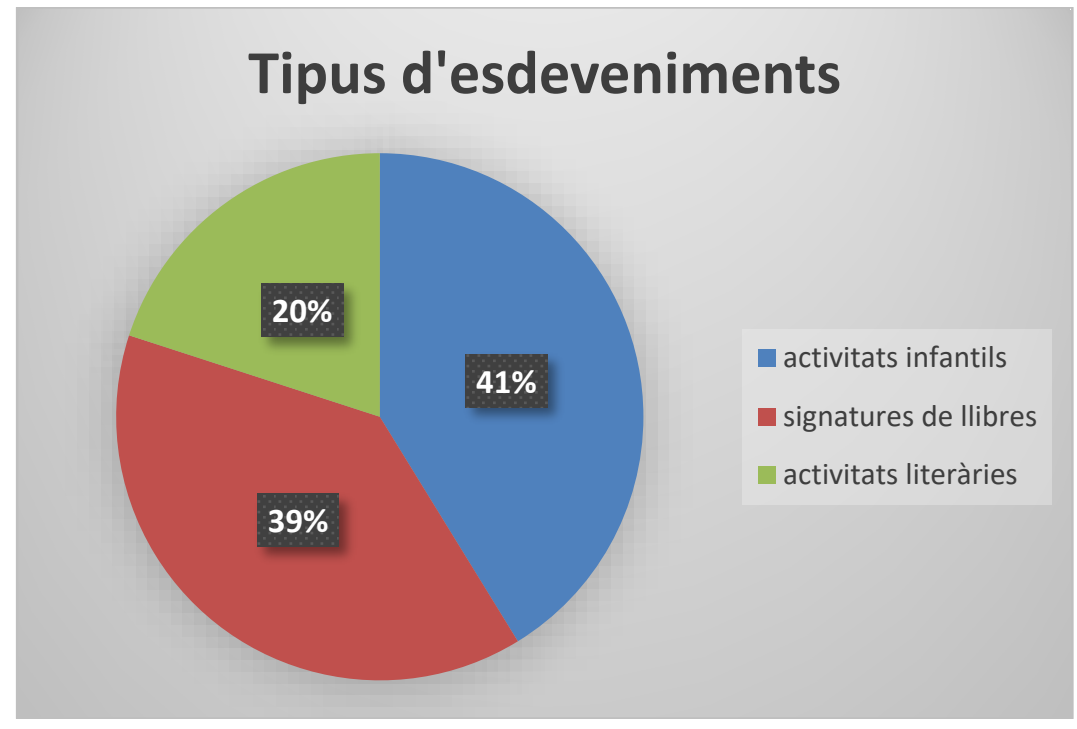

\section{CONCLUSIONS}

Més enllà d'estadístiques que, com ja hem exposat, són relativament parcials, si bé prou significatives de la realitat actual, cal dir que des de sempre l'activitat promocional forma part de l'ADN del sector llibreter. Amb major o menor freqüència, amb més o menys èxit, però sempre la majoria d'establiments, arrelats al seu entorn i plenament consolidats, tenen un compromís cultural ben definit. Potser encara no hem arribat a redissenyar i modernitzar el format dels actes. Ara entraríem en un debat ampli i complex sobre si la nova societat de la informació, amb tots els canvis produïts per la tecnologia, ens implicaria fer una reflexió seriosa, valenta i atrevida sobre la realitat actual, amb l'ànim de cercar la millor manera $d$ 'acostar el llibre i els seus autors a les joves generacions que es mouen $\mathrm{i}$ informen d'una manera diferent.

Personalment, crec que el món del llibre, i les llibreries en particular, no s'han mostrat mai impermeables a acostar-se amb decisió als nous sistemes de difusió i promoció: començant pels correus electrònics o la informació de les agendes a les respectives webs, passant pels newsletters, Facebook i els blogs, per acabar a Instagram. Avui podem observar com nombroses llibreries recomanen periòdicament llibres a través d'aquests sistemes, especialment el darrer que he esmentat. Això permet crear una xarxa virtual que enllaça directament $i$ de forma fàcil i constant amb els seus seguidors-lectors i també amb altres llibreries, editorials $\mathrm{i}$ autors que disposen i fan servir el mateix canal comunicatiu. Amb tot, la presència física i personal a la llibreria és un actiu que no es vol deixar perdre, malgrat que ara no és del tot indispensable. Sí que hi ha la percepció clara i transversal que anys enrere el públic participant en les presentacions

\author{
La majoria \\ d'establiments, \\ arrelats al seu entorn $i$ \\ plenament \\ consolidats, tenen un \\ compromis cultural \\ ben definit. Potser \\ encara no han arribat \\ a redissenyar $i$ \\ modernitzar el format \\ dels actes
}

\section{La presència física $i$ personal a la llibreria és un actiu que no es vol deixar perdre, malgrat que ara no és del tot indispensable}


clàssiques era més nombrós. No sabem, doncs, si tota aquesta activitat té un retorn econòmic clar, però, en qualsevol cas, es considera que els nous temps hi porten de manera inexorable.

Ho anirem veient...

Activitats a la llibreria Parcir (Manresa)
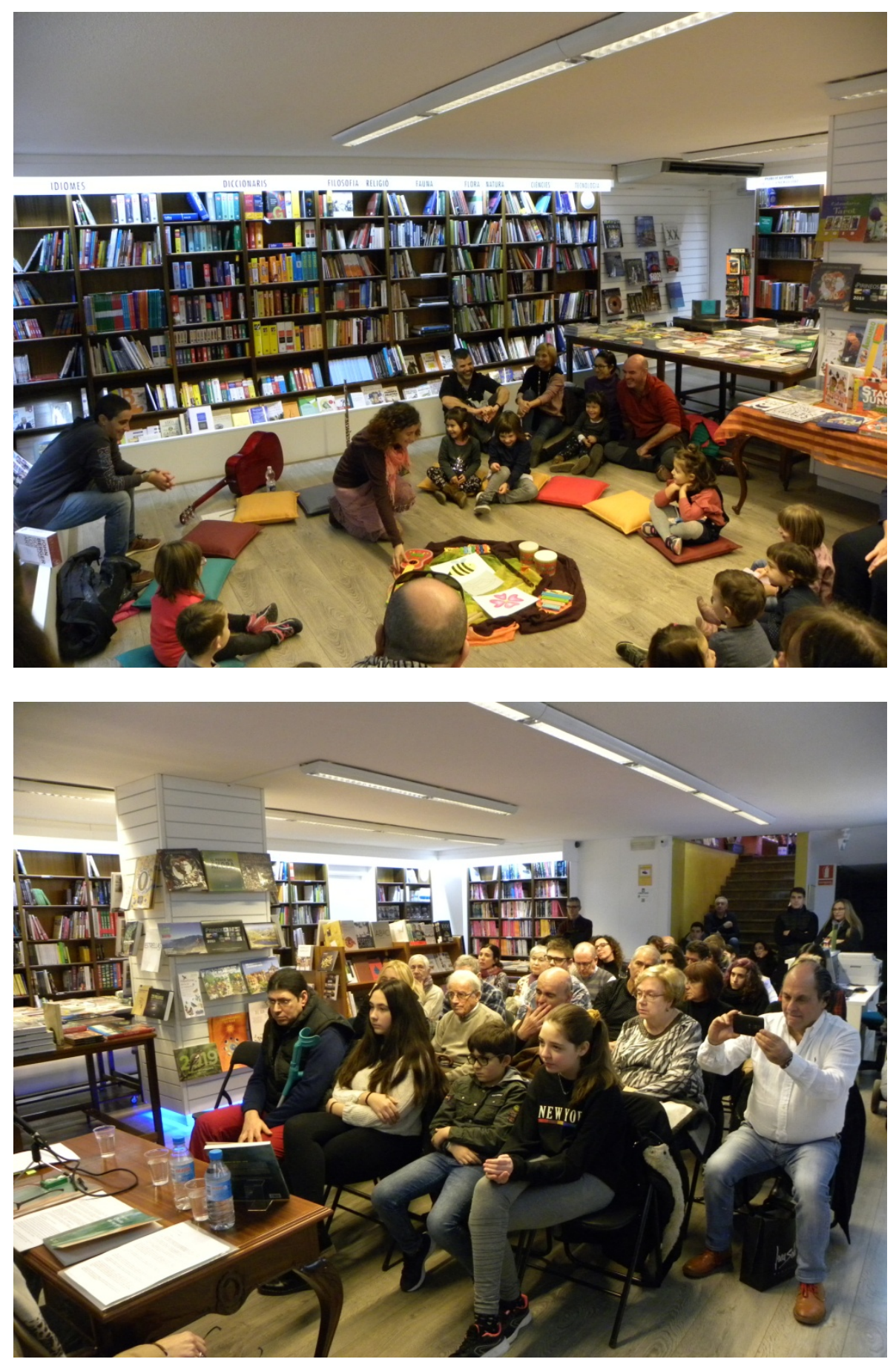


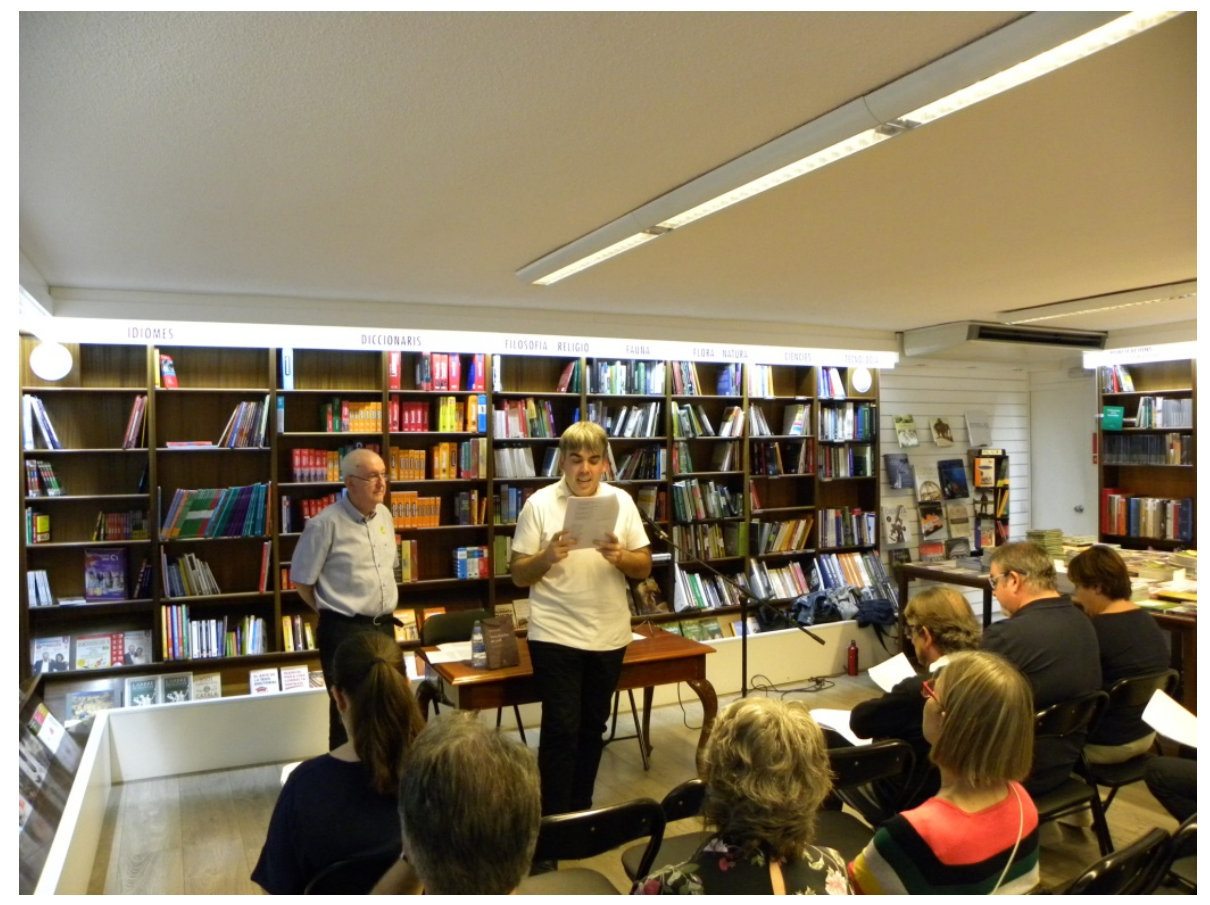

\section{BIBLIOGRAFIA}

Confederación Española de Gremios y Asociaciones de Libreros (2019). Observatorio de la Librería. Dirección y realización, Rafael Bravo Gil, Victoria Bordonaba Juste, José Miguel Pina Pérezm Iguácel Melero Polo. Zaragoza: CEGAL (Confederación Española de Gremios y Asociaciones de Libreros); Ministerio de Cultura y Deporte. $100 \mathrm{p}$.

$<$ https://www.cegal.es/wp-content/uploads/2019/11/Observatorio-de-laLibrer\%C3\%ADa-2019.pdf>.

Generalitat de Catalunya. Departament de Cultura (2016). Llibreria de referència de Catalunya. Barcelona: Departament de Cultura de la Generalitat de Catalunya.

<https://icec.gencat.cat/ca/campanyes/llibreria-de-referencial .

Generalitat de Catalunya. Departament de Cultura (2017). Pla de lectura 2020. Barcelona: Departament de Cultura de la Generalitat de Catalunya. 2 vol.

$<$ https://cultura.gencat.cat/ca/departament/plans-i-programes/ambitsectorial/pla-de-lectura-2020/>.

Generalitat de Catalunya. Departament de Cultura. ICEC. Àrea del Llibre (2016). Mapa de Llibreries de Catalunya. Miquel Flamarich (dir.). Barcelona: Àrea del LLibre, ICEC: Departament de Cultura de la Generalitat de Catalunya. 155 p.

$<$ https://icec.gencat.cat/ca/campanyes/llibreria-de-referencial>.

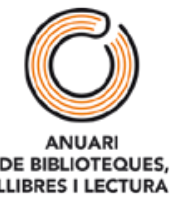


Disponible a:

https://revistes.ub.edu/index.php/Anuari-BLL/article/view/004

Daura i Jorba, Antoni «La promoció de la lectura a les llibreries de Catalunya (2018-2019)».

Anuari de Biblioteques, Llibres i Lectura, vol. 6 (2020), p. 34-48.

DOI 10.1344/ABLL.2020.6.004

Llicència Creative Commons

Reconeixement - NoComercial - SenseObraDerivada

(by-nc-nd): No es permet un ús comercial de l'obra

original ni la generació d'obres derivades.

(c) (1) (9) 
UNIVERSITAT De

BARCELONA

Facultat d'Informació

i Mitjans Audiovisuals

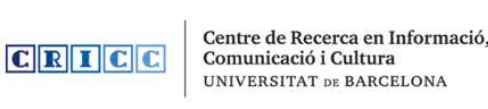

(O)

DE BIBLOTEOUES

\section{ANUARI \\ DE BIBLIOTEQUES, \\ LLIBRES I LECTURA \\ 2020}

Editors

Lluís Agustí

Maite Comalat

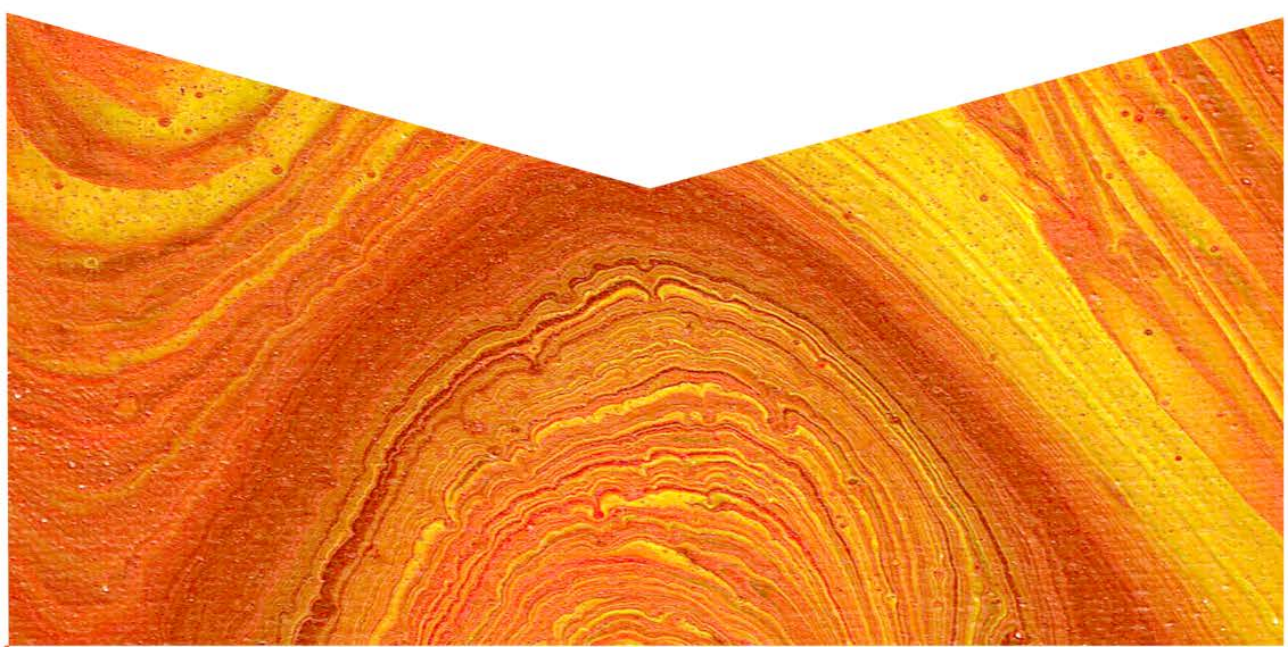

